\title{
HAPLOID INTERSEXES IN THE WASP HABROBRACON
}

R. C. VON BORSTEL and P. A. SMITH

Biology Division, Oak Ridge National Laboratory,* Oak Ridge, Tennessee

\section{INTRODUCTION}

Received 8.xii.59

A Locus responsible for sex determination is known in the parasitic wasp Habrobracon. Whiting (1943a) described nine alleles at this locus, any of which in pairwise combination produced diploid females, any of which when homozygous produced diploid males, and any of which when hemizygous in unfertilised eggs produced haploid males. It follows that half of the haploid males in a given stock are genotypically different from the other half with respect to sex alleles, although they are phenotypically indistinguishable.

Three different classes of sex intergrades have been observed in Habrobracon: gynandromorphs, individuals that are a composite of true haploid male and diploid female parts; gynandroids, haploid males mosaic for haploid nuclei of two different sex alleles ; and intersexes, individuals whose cells and tissues are of one chromosomal constitution yet which show feminisation of male tissue or masculinisation of female tissue.

Gynandromorphs usually come from eggs in which two meiotic products become pronuclei, one of them combining with a sperm and the other entering cleavage "asyngamate". They can, however, come from unfertilised eggs when two of the four meiotic products fuse and enter cleavage and either one or both of the remainder enter cleavage without fusing. They also can come from fertilisation of the egg with two sperms, one of which combines with the egg pronucleus and the other enters cleavage asyngamate. (See von Borstel, I957, for a review of the multiple causes of gynandromorphism.)

The gynandroids described by Whiting, Greb, and Speicher (1934) were understood genetically when the nature of sex allelism was established. At the boundaries between haploid male tissues of different sex allele composition, female tissue was formed, presumably by diffusion and complementation of agents produced by cells containing the different alleles. This phenomenon has now been recognised as operating in enzyme synthesis in Neurospora (Woodward, Partridge, and Giles, 1958).

The intersexes seem to have two different genetic derivations, each of which has been explained by assuming that mutations or chromosomal rearrangements have occurred at the sex locus. Whiting ( I946) described a diploid intersex - a masculinised female. To explain it, he proposed that a mutation of one of the sex alleles had occurred so

* Operated by Union Carbide Corporation for the U.S. Atomic Energy Commission. 
that complementation was imperfect. A haploid intersex, found twice previously (Whiting, I943 $b$; Whiting and Starrells, I950) was obtained under conditions that allowed a partial analysis of its composition. Whiting and Starrells postulated that the intersexes may have arisen from a translocation involving the sex locus with a consequent separation of the sex alleles. This would result in establishment of the two complementary alleles in one genome and thus produce haploids with both sex alleles in every somatic nucleus. In their argument diploidy became a further essential factor for femaleness because haploid intersexes rather than haploid females were produced. We discovered the intersex mutants during a routine test for translocations, so that the hypothesis of Whiting and Starrells could be tested. In the first two occurrences of these intersexes the wasp females that produced the offspring segregating into two classes (males and sex intergrades) died before their condition was discovered and therefore before they were mated. Unfortunately this again was the case.

\section{EXPERIMENTAL}

The mutant female that produced the intergrades occurred in an experiment designed to measure the frequency of inherited partial sterility (probably translocations) in sperm after $4000 \mathrm{r}$.

When the $F_{1}$ females from irradiated \# $70^{i}$ fathers crossed with \#33 wild type virgins were bred unmated to determine possible heterozygosity for mutations, one of the virgin females had I I normal sons and I 3 sex intergrades that resembled gynandromorphs since they had male heads and female abdomens. The wing-cell size and antennal length of these intergrades appeared to be typically male, and the behaviour of the wasp was distinctly male. They differed from gynandromorphs, however, in that the ovaries of the intergrades were saclike and undeveloped. It can be concluded, therefore, that these are true intersexes. The femaleness-to-maleness gradation from posterior to anterior of these individuals was in accord with the description of Whiting ( $1943 b)$.

The locus responsible for intersex production exhibited linkage with the orange locus (chromosome 2). Ten males were wild type and one was ivory eyed (an allele at the orange locus); three of the intersexes were wild type and ten were ivory eyed (table I). This mutation had occurred twice previously and both times the genetic construction of the cross was such that linkage to the same locus was detected. The first occurrence (Whiting, I $943 b$ ) was spontaneous in a cross of wild type with orange, and the second (Whiting and Starrells, I950) was induced by X-rays in a wild type female subsequently crossed with a male bearing the ivory allele of the orange locus. The linkage data from the three occurrences were analysed by coincidence $\chi^{2}$ to estimate the probability that each occurrence was at the same locus. For this, $\mathrm{P}=0.50$ and it is assumed the mutations are at the same position. Of 
the 69 intersexes, 13 showed crossing-over; and of the 63 males, 21 were cross-overs. Thus, 34 of 132 individuals were cross-overs. All the data indicate that the linkage of the intersex mutation to the orange locus is $0 \cdot 26$.

Hatchability and adult survival for the mother of the intersexes are shown in table 2. The wasps were raised in four broods. The first brood of II eggs (producing II adults) was discarded before the

TABLE I

Distribution of eye colours among intersexes and males in offspring of each occurrence of the intersex mutation

\begin{tabular}{|c|c|c|c|c|c|c|c|}
\hline & \multicolumn{2}{|c|}{$\begin{array}{l}\text { Whiting } \\
\left(\mathrm{s} 943^{b}\right)\end{array}$} & \multicolumn{2}{|c|}{$\begin{array}{l}\text { Whiting and Starrelis } \\
(\mathrm{I} 95 \mathrm{0})\end{array}$} & \multicolumn{2}{|c|}{$\begin{array}{l}\text { Present } \\
\text { occurrence }\end{array}$} & \multirow{2}{*}{ Total } \\
\hline & Black & Orange & Black & Ivory & Black & Ivory & \\
\hline Intersexes & I 7 & 5 & 29 & 5 & 3 & Io & 69 \\
\hline Males & 7 & I 7 & I 3 & I 5 & Io & I & 63 \\
\hline
\end{tabular}

intersex nature of some of the offspring was recognised. These I I are not included in table $\mathrm{I}$. The reduction in adult survival to $0 \cdot 8 \mathrm{I}$ is not consistent with the assumption that the female was heterozygous for a recessive lethal since adult survival in controls is normally about

TABLE 2

Hatchability and adult survival of eggs laid by mother of intersexes

\begin{tabular}{|c|c|c|c|}
\hline Viable eggs/total & $\begin{array}{c}\text { Hatchability } \\
\text { per cent. }\end{array}$ & Viable adults/total eggs & $\begin{array}{c}\text { Adult survival } \\
\text { per cent. }\end{array}$ \\
\hline $43 / 43$ & I 00 & $35 / 43$ & $0.8 \mathrm{I}$ \\
\hline
\end{tabular}

$0.85^{-0} \cdot 90$, and with a recessive lethal mutation adult survival should have been less than 0.50 . The deaths are presumed to have been accidental in this case (and in controls for that matter) since 7 of the 8 deaths were in one brood of 15 eggs. The lethality occurred during early larval and mid-pupal development, which is a common time of death when too many larvæ are crowded on one host caterpillar ( Io to I 2 larvæ per caterpillar is about maximum to ensure total survival). Six $F_{2}$ brothers of the intersexes were outcrossed to wild type females to determine whether some of the $F_{2}$ sons were heterozygous and the intersex condition was heritable through the normal-appearing males. The $\mathrm{F}_{3}$ daughters all had the expected normal hatchability and adult survival of offspring. All $\mathrm{F}_{4}$ adults were normal. 


\section{DISCUSSION}

The exact nature of these sex intergrades is not immediately obvious; consequently, two different hypotheses will be examined : (I) a translocation was induced involving the sex alleles, and (2) a mutation was induced that involved a modifier locus analogous in some respects to the transformer or intersex locus in Drosophila.

Whiting and Starrells (1950) proposed that a translocation could involve the sex locus (chromosome I) and the orange locus (chromosome 2). Under these conditions, the fertilised egg would become a normal female heterozygous for the translocation, and, accordingly, her offspring would be of four classes: (I) normal males, (2) males bearing the translocation, (3) haploid intersexes bearing both sex alleles, and (4) embryos bearing no sex alleles and presumed to be inviable.

Such a translocation would have to be very small, perhaps a transposition of the sex locus only, since classes (3) and (4) would be of the adjacent I segregation type, and these are invariably lethal through chromosome imbalance of the duplication-deficiency type when large pieces of the chromosomes are translocated.

There are several objections to the translocation hypothesis. First, if it had been a transposition in all three recorded cases, then it would have been unlikely that a small transposition of the sex alleles from chromosome I to the same position on chromosome 2 would have occurred three times in succession. Second, one-third of the viable offspring from a heterozygous female should be intersexes rather than one-half (table I) if the alternate and adjacent I segregation classes are equal. Third, the class (2) males should be viable and, when mated, should produce females heterozygous for the translocation; no such translocations appeared in the last recurrence of the haploid intersexes either as inherited partial sterility or production of more intersexes. Fourth, the hatchability, and probably the adult survival, of eggs from the $F_{1}$ virgins following radiation (table 2) is too high to admit the possible existence of any inviable class.

The second hypothesis, that a mutation was induced involving a modifier locus analogous in some respects to the transformer or intersex locus in Drosophila (the locus is 26 units from the orange locus on chromosome 2), is consistent with the known facts and is most easily reconcilable with the observation that each occurrence of the intergrade mutation has been in the same position on the chromosome.

The precedent for a mutation of this type is seen in the following mutations : $i x$ and tom (renamed $i x^{2}$, Meyer, I958) on the second chromosome and $\mathrm{Hr}$ and tra on the third chromosome of Drosophila melanogaster ; $I x^{\mathrm{B}}$ on the second chromosome and Lebedeff's recessive on the third chromosome of $D$. virilis ; Sturtevant's recessive intersex mutation in D. simulans; and Dobzhansky and Spassky's dominant intersex in $D$. pseudoobscura (reviewed in part by Kroeger, 1959, and 
in part by Gowen and Fung, I 957). In every case genetic females are transformed toward or into phenotypic males. In the wasps Mormoniella (Saul, I960) and Habrobracon, however, genetic males are transformed toward phenotypic females by the presumed intersex gene. As in all the transformed or intersexual Drosophila and the intersexual Habrobracon, the gonads of Mormoniella are reduced to almost vestigial structures. The one case in Habrobracon for a female-to-male intersex should not be considered in this context since, according to Whiting (1946), it is possible that the sex allele itself had been mutated. The only suggested case that does not follow the general rule for a female-to-male sex shift in Drosophila was that of the $B d-M$ combination (Goldschmidt, I947, I949), but this was disputed by Sturtevant (1949) on the grounds that these individuals merely had underdeveloped male genitalia. Kroeger (I96o) based a strong argument for Sturtevant's contention on the finding that, although the $B d-M$ combination produces only underdeveloped males, an environmental effect in conjunction with the $f a^{n o}$ mutation yields a graded series of underdeveloped, through normal, to overdeveloped male genitalia. Thus it seems that no clear cases for male-to-female intersexuality exist in Drosophila, whereas female-to-male intersexual mutations have appeared a number of times in several of the Drosophila species. It can be concluded that the relation between sex-modifying genes and the direction of change that they produce in the wasps is the reverse of that found in Drosophila.

Furthermore, in the Habrobracon intersexes, a female-to-male gradient exists from the posterior toward the anterior end; whereas in Drosophila ix mutations, the reverse is observed (Kroeger, I959). Another gene, gynoid (chromosome I), that exhibits certain characteristics of intersexuality in Habrobracon by showing a weak male-towardfemale transformation does not show this type of gradient. Gynoid males, although they have shortened antennæ and thickened abdominal tergites and sternites, have male ocelli and genitalia and exhibit normal mating behaviour and fertility (Whiting, Greb, and Speicher, I 934). If any morphological gradient exists at all in gynoid mutants, the tergites and sternites in the anterior of the abdomen look a little more female and grade to a more male appearance toward the posterior, thus being the reverse of the other Habrobracon intersex mutants and indicating that any generalisations based on a posterior-to-anterior gradient may be spurious.

The question arises as to the relation of intersexuality genes to sex determination. This has been discussed at length elsewhere (see for instance, Gowen and Fung, I957, and Goldschmidt, I955, pp. 9o-94 and 448-45I) and is beyond the scope of this paper. It is possible that the intersex gene in Habrobracon suppresses or releases to a certain degree the action or complementary activity of the sex locus. Final resolution of this problem will probably have to await elaboration of the biochemical basis of sex determination. 


\section{SUMMARY}

During a routine analysis for radiation-induced recessive lethal mutations and translocations, a female was found that produced haploid intersex offspring. These intersexes showed linkage with the orange locus of chromosome 2, as had two previous occurrences of this type of intersex. The intersexes were shown not to have derived from a separation of the sex alleles by a translocation. It is suggested that a gene was mutated that is in some respects analogous to the genes for intersexuality found in different species of Drosophila. The action in Habrobracon would appear to be from male-toward-female rather than the reverse as in Drosophila.

Acknoweledgments. - The authors wish to express their gratitude to Drs G. E. Brosseau, A. M. Clark, M. E. Gaulden, H. Kroeger, W. J. Welshons, and P. W. Whiting for critically reading the manuscript. In particular, Drs Kroeger and Whiting have been exceedingly helpful through our many discussions.

\section{REFERENCES}

VON BORSTEL, R. C. I957. Nucleocytoplasmic relations in early insect development. In The beginnings of embryonic development, ed. A. Tyler et al., pp. I 75-199. American Association for the Advancement of Science, Washington, D.C.

Goldschmidt, R. I947. New facts on sex determination in Drosophila melanogaster. Proc. Nat. Acad. Sci. U.S., 34, 245-252.

GOLDSGhmidT, R. I949. The Beaded-Minute intersexes in Drosophila melanogaster Meigen. F. Exp. Zool., 112, 233-30I.

goldschmidt, R. 1955. Theoretical genetics. University of California Press, Berkeley, Calif.

GOWEN, J. W., AND FUnG, s. T. G. 1957. Determination of sex through genes in a major sex locus in Drosophila melanogaster. Heredity, II, 397-402.

KROEGER, H. 1959. The genetic control of genital morphology in Drosophila : a study of the external genitalia of sex mosaics. W. Roux' Arch.f. Entwickl.-mech. d. Organ., 151, 30 I-322.

KROEGER, H. I96o. Hypo- and hyperdevelopment of the male genital apparatus and the Bd-M combination in Drosophila melanogaster. 7. Morphol., in press.

MEYeR, H. U. I958. New mutants. Dros. Inf. Serv., 32, 83.

SAUL, G. I96o. Haploid intersexes in Mormoniella (in preparation).

sturtevant, A. H. I949. The Beaded-Minute combination and sex determination in Drosophila. Proc. Nat. Acad. Sci. U.S., 35, 3 I I-3 I 3.

whiting, P. w. I943a. Multiple alleles in complementary sex determination of Habrobracon. Genetics, 28, 365-382.

Whiting, P. w. I943b. Intersexual females and intersexuality in Habrobracon. Biol. Bull., 85, 238-243.

Whiting, P. w. I946. A strongly intersexual female in Habrobracon. Biol. Bull., $9 r, 243-246$.

WHITING, P. W., GREB, R. J., AND SPEICHER, B. R. I934. A new type of sex-intergrade. Biol. Bull., 66, I52-165.

WHITING, P. W., AND STARRELLS, R. I950. Evidence for haploid intersexual females in Habrobracon. Amer. Nat., 84, 467-475.

Woodward, D. O., Partridge, C. W. H., AND Giles, N. H. I958. Complementation at the ad-4 locus in Neurospora crassa. Proc. Nat. Acad. Sci. U.S., 44, I237-1 244. 